\title{
Technology Maturity Forecasting of Thermostat based on Patent Analysis
}

\author{
Z.G. XU \\ School of mechanical engineering, Shandong University, China
}

Q. WU

College of management engineering, Guangxi University of Science and Technology, China

Z.X. LI

School of mechanical engineering, Shandong University, China

\begin{abstract}
Technology forecasting plays a fatal role for enterprise survival and development. Technology maturity of thermostat is predicted with the TMMS and patent data algorithms. Radar plot is drawn to indicate the evolutionary potential for the further improvements of thermostat. It is pointed out that thermostat will be getting more dynamic and smaller with the help of radar plot.
\end{abstract}

KEYWORD: radar plot; thermostat; technology forecasting

\section{INTRODUCTION}

Vehicle and engine technology has make a great progress with the development of traffic life, at the same time, the cooling system as an important subsystem of vehicle and engine, also plays a important role[1]. The thermostat is used as a core component of automobile cooling system, pressure drops to adjust the bypass pipeline, thereby regulates the flow of cooling liquid in tank and bypass[2]. Thermostat ensures the normal work of fuel consumption, reliability etc. Its development attracted great attention of the automotive industry. Therefore, to predict thermostat technology, clarifies the technology development trend, accelerates technology development[3]. Breakthrough in thermostat technology is to realize high efficiency, lower consumption of the cooling system, and enhance the overall performance of internal combustion engines. This technology forecasting is drawing more and more attentions world wide[4].

TMMS prediction model is combined with patent data measurement methods for technical maturity forecasting. Technology evolution radar chart is drawn for the analysis of technique evolution trend, which is useful for enterprises to understand product technology maturity, and the product development and innovation trend is found[5].

\section{TMMS PREDICTION MODEL}

Technology maturity measuring system (TMMS for short) is used to predict technology development trend. G.S.Altshuller based on the investigation and analysis of a large number of patents, found the product evolution meeting curves, and the product evolution is divided into four periods, i.e. infant period, growth period, mature period and withdrawal period. And research works found the relationships among four index, i.e. technical system evolution model, product performance/ profitability, the patent number and patent grade [6-7].
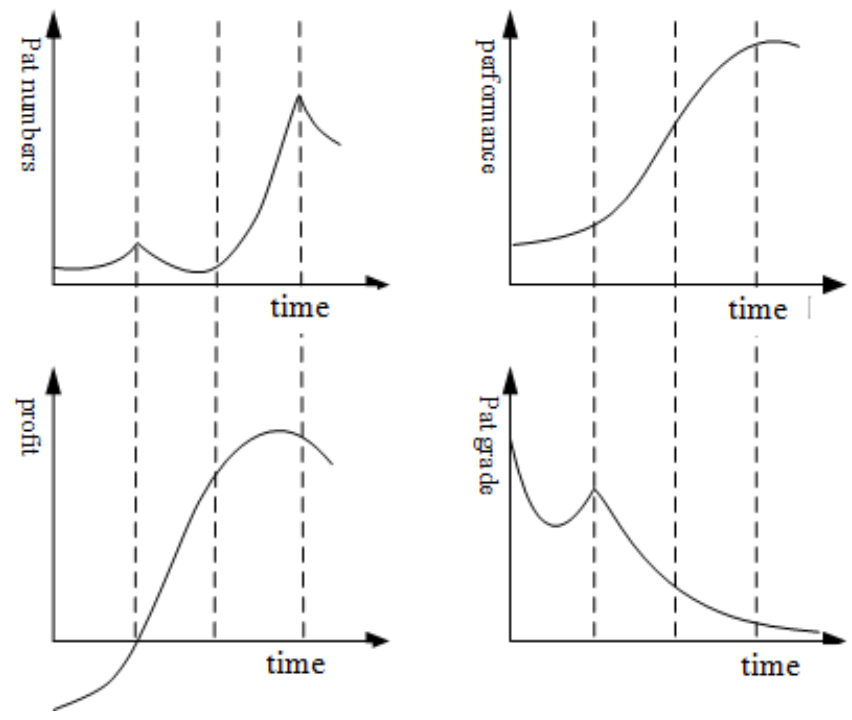

Figure 1. Standard patent prediction curves

The curve shapes changed with four indicators, which can predict the technology maturity, as shown in figure 1 .

TMMS technology maturity predicting model is based on G.S.Altshuller and Darrell Mann. The patent investigation results are used in the research results, laid down the theoretical prediction basis, where three numbers are introduced, i.e. the patent number (PN), patent level (PL), the number of patent remedy defects $(\mathrm{SCP})[8]$. 
The number of patents, patent level make up defects of three standard curves in Figure 2, obviously, the three indicators were derived from a data source, to visit a number of aspects of a problem[9-10].

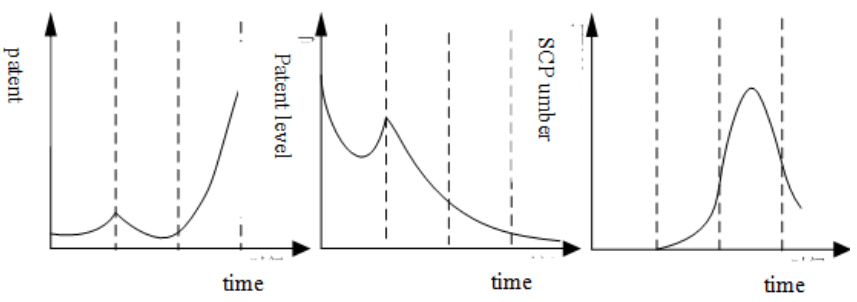

Figure 2 TMMS prediction curve

TMMS system is based on the extremum points of patent technology in the life cycle division characteristic curve, which is divided into seven stages.

The slope of each curve characteristics is combined with SCP feature in the same period, the proportion of patents in the combination gives the forecasting evidence for the technology maturity. Combination of different features in the technology maturity criterion is used for prediction, and it is the core algorithm [11] used in the TMMS system.

Table 1Product combination maturity prediction

\begin{tabular}{|c|c|c|c|c|}
\hline maturity & $\begin{array}{c}\text { Pat num } \\
\text { cure slope }\end{array}$ & $\begin{array}{c}\text { Pat grade } \\
\text { cure slope }\end{array}$ & $\begin{array}{c}\text { MUDPQ } \\
\text { cure slope }\end{array}$ & $\begin{array}{c}\text { PMUDP } \\
\text { cure slope }\end{array}$ \\
\hline Pro-infant & $\geqslant 0$ & $\leqslant 0$ & & Very few \\
\hline Post-infant & $\geqslant 0$ & $>0$ & & Very few \\
\hline Pre-growth & $<0$ & $\leqslant 0$ & $\geqslant 0$ & less \\
\hline Post-growth & $\geqslant 0$ & $\leqslant 0$ & $\geqslant 0$ & partial \\
\hline Pre-mature & $\geqslant 0$ & $\leqslant 0$ & $\geqslant 0$ & most \\
\hline Post-mature & $\geqslant 0$ & $\leqslant 0$ & $<0$ & most \\
\hline withdrawal & $<0$ & $\leqslant 0$ & $<0$ & partial \\
\hline
\end{tabular}

* MUDPQ stands for making up for the defect of patent quantity.

* PMUDPQ, means proportion of MUDPQ in total patents of the same period.

\section{QUANTITATIVE MEASUREMENT OF PATENT NUMBER}

Quantitative calculation of the number of patents is used in technology forecasting, where. $V$ is the growth rate; $\alpha$ is the technology mature coefficient, $\beta$ is the technology aging coefficient, and $N$ is the new technology of feature coefficient, the calculation formula is as follows:

$$
\begin{gathered}
v=\frac{a}{A} \\
\alpha=\frac{a}{a+b}
\end{gathered}
$$

$$
\begin{aligned}
& \beta=\frac{a+b}{a+b+c} \\
& N=\sqrt{v^{2}+\alpha^{2}}
\end{aligned}
$$

Where, a, b, c is invention patents, utility model and patent number respectively, and $\mathrm{A}$ is the number of appearance patents; the numbers is within 5 years period.

According to the formula in (1),(2),(3),(4), if $\mathrm{V}$ is growing up, the technology is in the growth stage, if $\alpha$ is getting smaller every year, then the technology is mature, if $\beta$ is getting smaller, the technology is in the aging period [12]. In addition, the bigger the $N$ value, it indicated that the new technology features more stronger.

In this paper, TMMS prediction model is combined with the patent number measuring algorithm in the technical maturity prediction. This method reduces the difficulty in data collection, and increases the technology prediction accuracy[13].

The Chinese patent search engine, i.e. SooPat China database is used in this analysis. SooPat Chinese patent data is connected with the State Intellectual Property Office of Internet search database. SooPat is within the Internet patent database, is suitable for the integrating and adjustment for patent data acquisition.

\subsection{Patent data collection}

"Thermostat" is used for patent search keyword in the patent title, patent data is within 2003-2012. 220, patents are obtained as shown in table 2 .

In order to increase the prediction accuracy, three types of patents, i.e. invention patents, utility model patents and appearance patents, are separately collected and classified to calculate four parameters of $V, \alpha, \beta, N$, as shown in table 3 [14].

Table 2 summary of classification of patent number

\begin{tabular}{|c|c|c|c|c|}
\hline Order & Time & Pat numbers & Patent level & SCP \\
\hline 1 & 2000 & 0 & & 0 \\
\hline 2 & 2001 & 0 & & 0 \\
\hline 3 & 2002 & 2 & 1 & 1 \\
\hline 4 & 2003 & 0 & & 0 \\
\hline 5 & 2004 & 1 & 1 & 0 \\
\hline 6 & 2005 & 4 & 1.25 & 2 \\
\hline 7 & 2006 & 3 & 1.33 & 2 \\
\hline 8 & 2007 & 8 & 1.25 & 5 \\
\hline 9 & 2008 & 17 & 1.18 & 10 \\
\hline 10 & 2009 & 17 & 1.24 & 12 \\
\hline 11 & 2010 & 16 & 1.06 & 8 \\
\hline 12 & 2011 & 64 & 1.09 & 27 \\
\hline 13 & 2012 & 88 & 1.04 & 33 \\
\hline
\end{tabular}


Table 3 the thermostat Technology $V, \alpha, \beta, N$ in statistics

\begin{tabular}{|c|c|c|c|c|c|c|c|c|}
\hline year & 05 & 2006 & 2007 & 2008 & 2009 & 2010 & 2011 & 2012 \\
\hline $\mathrm{v}$ & 1 & 0.67 & 0.4 & 0.44 & 0.44 & 0.12 & 0.38 & 0.19 \\
\hline$\alpha$ & 0.2 & 0.67 & 0.29 & 0.31 & 0.41 & 0.18 & 0.26 & 0.19 \\
\hline$\beta$ & 1 & 1 & 0.88 & 0.76 & 1 & 0.69 & 0.53 & 0.31 \\
\hline & 1.03 & 0.95 & 0.49 & 0.54 & 0.6 & 0.22 & 0.46 & 0.27 \\
\hline
\end{tabular}

The TMMS model is used after data collection, the index statistics, select three or four times curve was fitted according to the curve shape, the generated curves are shown in figure 3, figure 4, figure 5 .

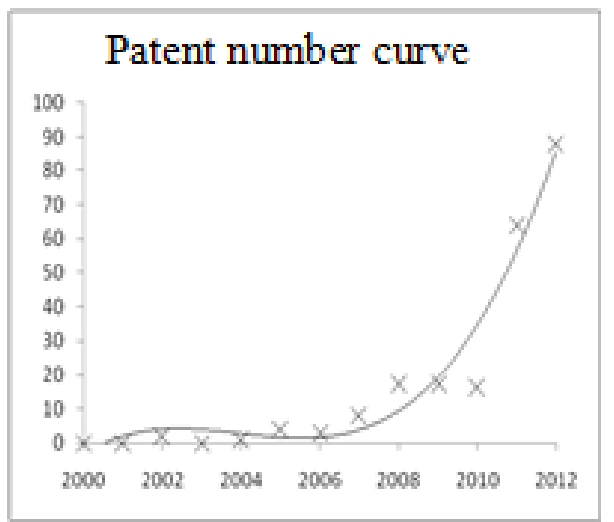

Figure 3 thermostat Patent number curve

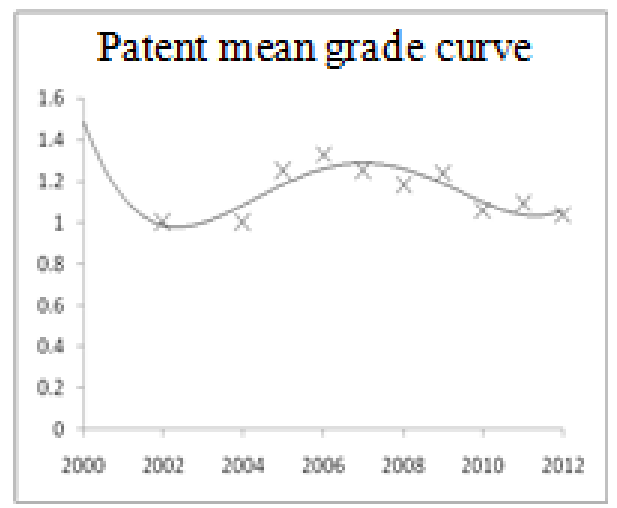

Figure 4 thermostat Patent mean grade curve

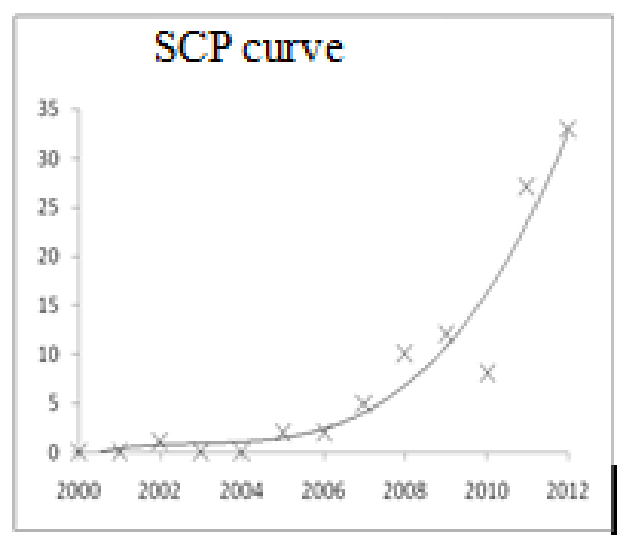

Figure 5 thermostat SCP curve

In order to increase the prediction reliability, data in Table 2 are used to generate the 4 fitting curves in figure 6 .

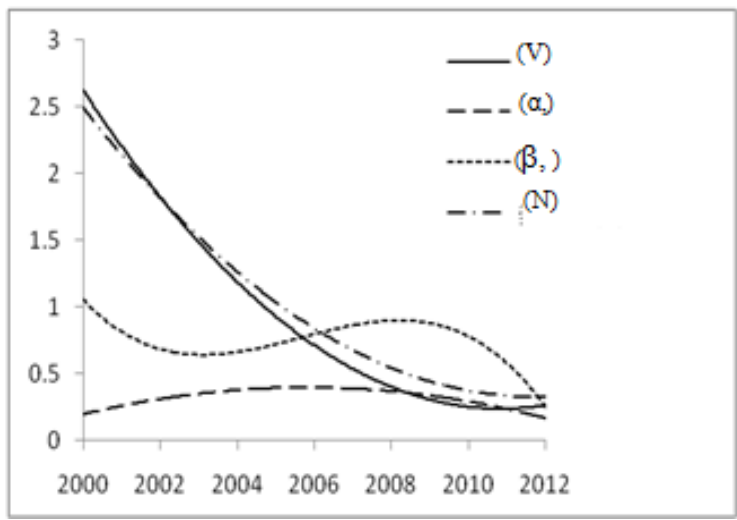

Figure 6. $V, \alpha, \beta, N$ in the graph

\section{TECHNICAL MATURITY PREDICTION}

The generated curves roughly gives the development trend for future years, and the patent characteristic curve shows that it is in the mature period, which coincides with the early part of the curve. And from Figure 3, it could be found that $V, \alpha, \beta, N$ curve decreased in 2008 after the trend observed at the same time, the change trend of the thermostat of these parameters is further corroboration of the technology forecasting method[15].

The above two analysis methods shows that, the thermostat technology of vehicle cooling system experienced in the infant stage, growth stage, has just entered the mature period. This paper adopts the technology of the next evolutionary potential map, description and technical analysis system of thermostat evolutionary status.

\section{RADAR PLOT OF THERMOSTAT}

The radar plot is drawn from 220 copies of thermostat related patents, research on analysis and generalization is carried out, which can simplify the evolutionary potential trend. In order to describe technology evolution potential routes, radar map is shown in figure 7 .

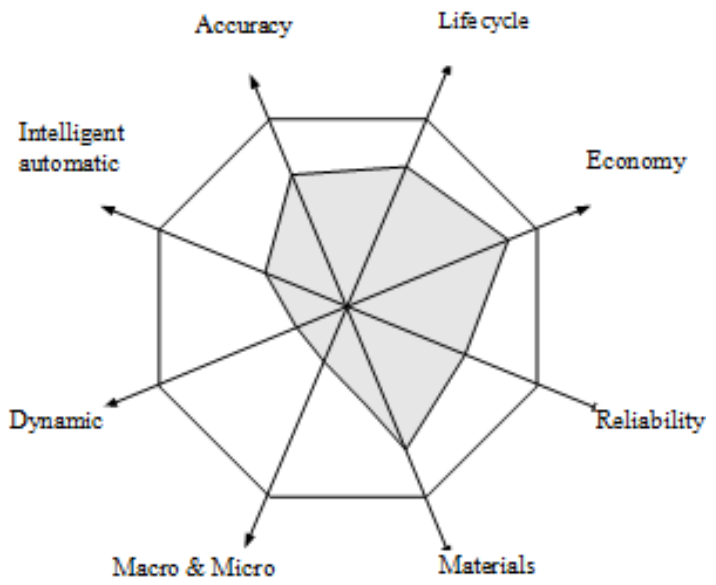

Figure 7 Radar plot of thermostat 
According to the evolutionary radar map, five aspects are in full level, i.e. There are little development potentials, but the controllability, dynamic, from the macro to the micro aspects of evolutionary level is still low, can provide guidance for the development of research in technology the lower level. Clearly the potential technology evolution diagram, explain the thermostat technology has great evolutionary potential, can provide guidance for the development of the thermostat.

\section{SUMMARY}

The TMMS model and the patent quantity measure method is combined to predict auto thermostat technology maturity, reducing the error of TMMS model as the result of some subjective factors when in use, reduces the difficulty of obtaining the data, but increased the accuracy of the prediction results. In addition, the development trend of the application of technology evolution potential map analysis of automobile thermostat technology, is helpful for the formulation of development strategies and thermostat, and the direction of improvement and innovation is to guide the enterprises.

\section{ACKNOWLEDGMENTS}

The above-mentioned research work is supported by the Chinese NSFC, 61272017, P.R. China, and the Key Laboratory of High-efficiency and Clean Mechanical Manufacture at Shandong University, Ministry of Education.

\section{REFERENCES}

[1] H Dou, V Leveill, S Manullang, et al, Patent analysis for competitive technical intelligence and innovative thinking. Data science journal, 2005, 4 (3): 209 237.

[2] Sungjoo Lee, Seonghoon Lee, Hyeonju Seol, et al, Using patent information for designing new product and technology: keyword based technology road mapping. R\& D Management, 2008, 38(2): 169 188.

[3] Yan Li, Jian Wang, Xianglong Li, et al, Design creativity in product innovation. The International Journal of Advanced Manufacturing Technology, 2007, 33(3-4), 213 222.

[4] W. Y. Zhang, S. 'B. Tor, G. A. Britton and Y.-M. Deng. A Knowledge-Based Expert System for Functional Design of Engineering Systems. Engineering with Computers (2001) 17: 339 353.

[5] Chuang, Y., Lee, L., Hung, W., \& Lin, P. (2010). Forging into the innovation lead - A comparative analysis of scientific capacity. International Journal of Innovation Management, 14(3), 511 529.

[6] Kostoff, R. N., Briggs, M. B., Rushenberg, R. L., Bowles, C. A., Icenhour, A. S., Nikodym, K. F., et al. (2007). Chinese science and technology - Structure and infrastructure. Technological Forecasting and Social Change, 74, 1539 1573.

[7] Kumar, N., \& Asheulova, N. (2011). Comparative analysis of scientific output of BRIC countries. Annals of Library and Information Studies, 58, 228 236.

[8] Lall, S., \& Teubal, M. (1998). Market stimulating technology policies in developing countries: A framework with examples from East Asia. World Development, 26, 1369 1385.

[9] Leydesdorff, L., Wagner, C. S., \& Bornmann, L. (2014). The European Union, China, and the United States in the Top-1\% and Top-10\% layers of most-frequently cited publications: Competition and collaborations. Journal of Informetrics, 8, 606 617.

[10] Merges, R., \& Nelson, R. R. (1994). On limiting or encouraging rivalry in technological progress: The effect of patent-scope decisions. Journal of Economic Behavior and Organization, 25, 1 24.

[11] Meyer, M. (2000). Does science push technology? Patents citing scientific literature. Research Policy, 29, 409 434.

[12] Rosenberg, N. (1974). Science, invention and economic growth. The Economic Journal, 84, 90 108.

[13] Tseng, C.-Y. (2009). Technological innovation in the BRIC economies. Research-Technology Management, 52, 29 35.

[14] Rost, K., 2010. The strength of strong ties in the creation of innovation. Research Policy 40, 588 605.

[15] Ryan, L., 2012. An investigation of product service system models. International Journal of Service Science, Management, Engineering, and Technology (IJSSMET) $3.2,35 \sim 49$. 